\title{
DINÂMICA DA AGRICULTURA E \\ DESENVOLVIMENTO NO \\ RIO GRANDE DO SUL
}

Benedito Silva Neto ${ }^{1}$

Telmo Rudi Frantz ${ }^{2}$

Resumo - O papel fundamental desempenhado pelas atividades econômicas não-agrícolas no desenvolvimento rural brasileiro tem sido evidenciado por vários estudos. O presente trabalho tem como objetivo analisar a hipótese de que uma parte importante das atividades não-agrícolas presentes no meio rural da maioria dos municípios do Rio Grande do Sul foi originada pela demanda de bens e serviços da própria população destes municípios. Uma análise da formação dos municípios ao longo da história do Rio Grande do Sul indicou que a densidade demográfica, assim como o nível e a distribuição da renda dos agricultores são variáveis importantes para explicar o seu desenvolvimento. A partir destas constatações elaborou-se um modelo matemático analítico que permitisse explicitar as relações destas variáveis (população rural, nível e distribuição da renda) com a demanda de bens e serviços locais. Os resultados obtidos no trabalho, especialmente as implicações formais dos modelos formulados, indicam que a manutenção da população no campo, a ampliação da renda dos agricultores e a promoção de uma melhor distribuição desta renda, podem ser elementos importantes de uma política de estímulo a atividades nãoagrícolas no meio rural, o que, no entanto, não exclui a necessidade de medidas específicas de apoio à criação de atividades não-agrícolas como, por exemplo, crédito, assistência técnica e capacitação de recursos humanos.

\footnotetext{
1 Professor Doutor do Departamento de Estudos Agrários - UNIJUÍ. E-mail: bsneto@unijui.tche.br.

2 Professor Doutor do Departamento de Estudos da Administração - UNIJUÍ. E-mail: Ifrantz@unijui.tche.br.
} 
Palavras-chave: desenvolvimento rural, modelo econômico, economia rural.

\section{Introdução}

O papel fundamental desempenhado pelas atividades econômicas não-agrícolas no desenvolvimento rural brasileiro tem sido evidenciado por vários estudos, o que se constitui em um dos avanços mais importantes nos campos da economia e da sociologia rural nos últimos anos. O presente trabalho, de caráter exploratório, tem como objetivo analisar a hipótese de que uma parte preponderante das atividades não-agrícolas presentes no meio rural da maioria dos municípios do Rio Grande do Sul foi originada pela demanda de bens e serviços da própria população destes municípios. Especificamente, é analisada a possibilidade de que os efeitos econômicos "induzidos" (MICHAÏLOF \& BRIDIER, 1987) pela renda agropecuária, na forma de geração de uma demanda de bens e serviços passíveis de serem produzidos localmente, poder ser um elemento importante para o desenvolvimento de atividades não-agrícolas no meio rural. Portanto, a diminuição da renda dos agricultores e da ocupação da mão-de-obra na agricultura podem ser consideradas obstáculos e não estímulos à criação de atividades não-agrícolas, como sustentam alguns autores (por exemplo DEL GROSSI \& GRAZIANO, 2000 e LAURENTI, 2000).

Este trabalho está dividido em duas partes. Na primeira parte procurou-se analisar sucintamente algumas características do desenvolvimento rural do Rio Grande do Sul e, a partir disto, identificar as principais variáveis responsáveis por este processo. Na segunda parte foi desenvolvido um modelo que permitisse analisar formalmente as possíveis relações entre as variáveis identificadas na primeira parte e a demanda de bens e serviços locais.

\section{1 - O desenvolvimento rural do Rio Grande do Sul}

WANDERLEY (2001), estudando as relações entre urbanização e ruralidade no Estado de Pernambuco concluiu que a grande 
maioria dos municípios deste Estado é "rural", situando entre 20.000 e 50.000 o número mínimo de habitantes para que o que convencionalmente se denomina de "perímetro urbano" dos municípios possa ser considerado como uma "cidade". Esta mesma autora cita vários outros estudiosos que adotam critérios semelhantes para analisar a "ruralidade" dos municípios brasileiros, especialmente os localizados no Nordeste.

Entretanto, é no estudo de VEIGA et alii (2001) que foi encontrada a análise mais exaustiva das repercussões econômicas da "ruralidade" de boa parte dos municípios brasileiros. Este autor analisou os critérios atualmente adotados nas estatísticas oficiais para definir a população urbana dos municípios brasileiros menos populosos, comparando-os com os critérios vigentes em outros países e concluiu que os critérios oficiais para a definição de populações urbanas no Brasil mascaram o fato de que o chamado "êxodo rural" na verdade corresponde, em boa parte, ao crescimento da população de municípios por ele classificados como "rurais", o qual é um indicativo de um importante desenvolvimento rural verificado no Brasil nas últimas décadas. Segundo este autor, o que se convencionou chamar de "perímetro urbano" de municípios que possuem menos de 20.000 habitantes não pode ser considerado, rigorosamente, como uma "cidade", na medida em que a sua população mantém profundos vínculos com o meio rural.

No caso do Rio Grande do Sul, incluindo-se na população rural a população residente no perímetro urbano dos municípios de menos de 20.000 habitantes, conforme proposto pelos autores citados acima (VEIGA et alii, 2001; WANDERLEY, 2001), observa-se que esta população apresenta um pequeno crescimento nas décadas de 80 e 90, conforme pode-se constatar na Figura 1 (onde a população rural do Estado adicionada à população residente no perímetro urbano nos municípios de menos de 20.000 habitantes é denominada de "população rural corrigida"). Nesta mesma Figura 1 pode-se observar que a população rural medida segundo os critérios oficiais (denominada na figura de "população rural oficial") apresentou neste período uma queda significativa, seguindo a tendência dos anos 70 . 
REVISTA DE ECONOMIA E SOCIOLOGIA RURAL. VOL. $41 \mathrm{~N}^{\circ} 3$

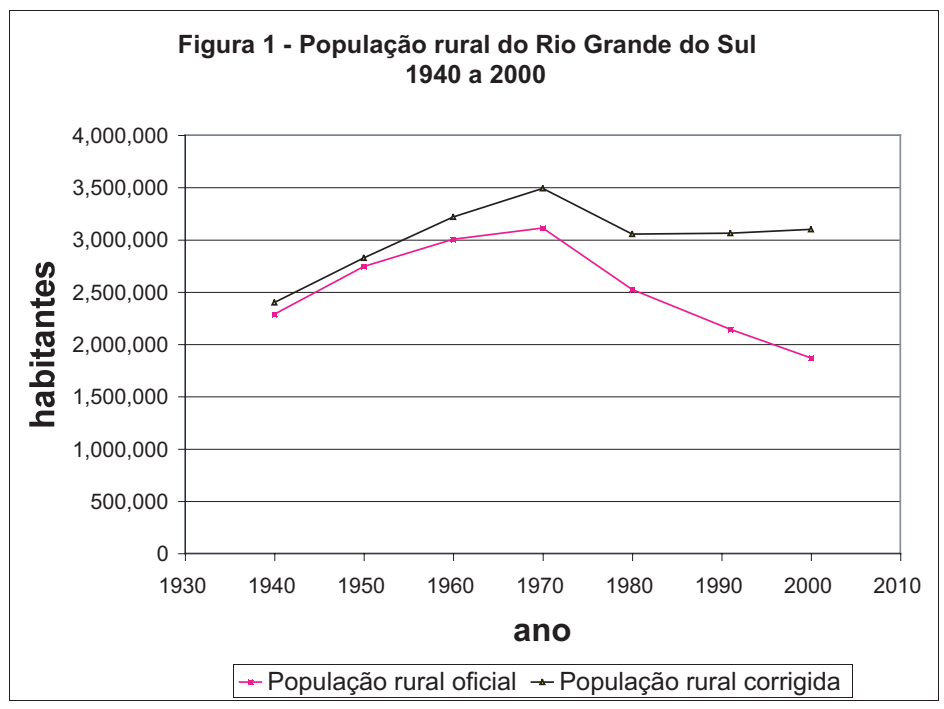

Fonte dos dados: JARDIM (2001).

Esta diferença de comportamento pode ser explicada pelo crescimento da população, total e residente no perímetro urbano, dos municípios de menos de 20.000 habitantes, observado a partir de 1.950, conforme mostrado na Figura 2. Assim, pode-se afirmar que a população rural do Rio Grande do Sul tem se concentrado de maneira crescente em pequenos municípios, cujas sedes, embora não possam ser consideradas "cidades", possuem uma certa diversidade de atividades econômicas. A constatação desta concentração é ainda reforçada pelo fato de o crescimento da população do conjunto dos municípios "rurais" (isto é, com menos de 20.000 habitantes) nos anos 80 e 90 (conforme mostrado na Figura 2) ter sido acompanhado por um vigoroso processo de criação de novos municípios, conforme podese constatar pelo aumento do número de municípios no Rio Grande do Sul mostrado na Figura 3. Além disto, pela análise de dados populacionais apresentados por JARDIM (2001) constatou-se que nenhum município do Rio Grande do Sul criado a partir de 1981 possuía mais do que 20.000 habitantes em seu primeiro recenseamento. Ou seja, os municípios criados nas últimas décadas no Rio Grande do 


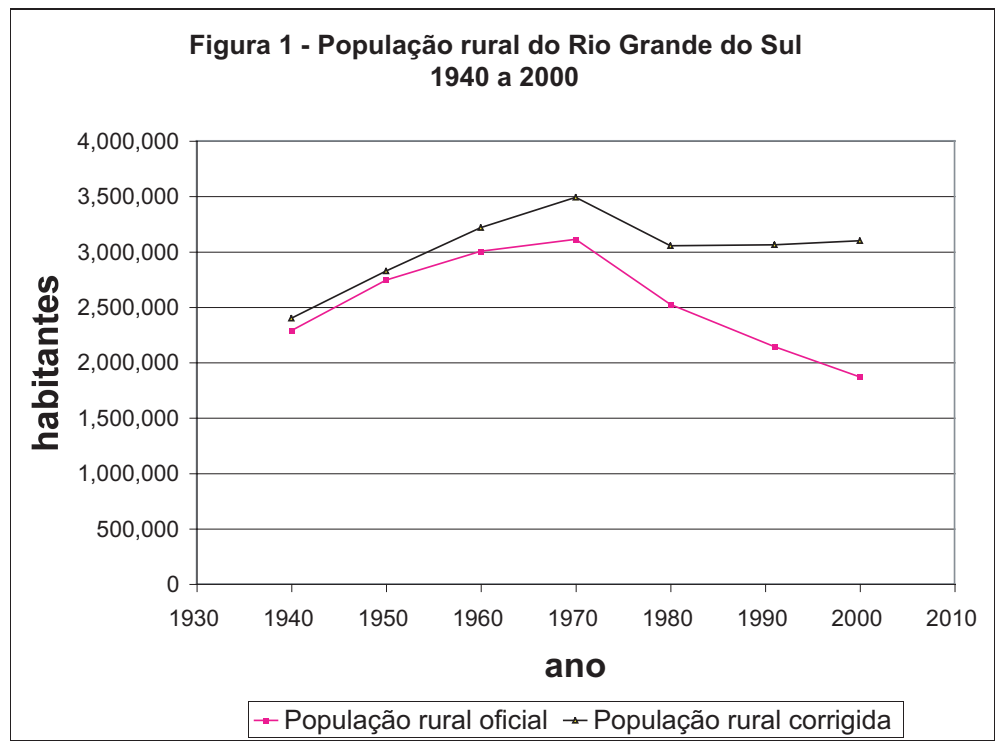

Fonte dos dados: Jardim (2001).

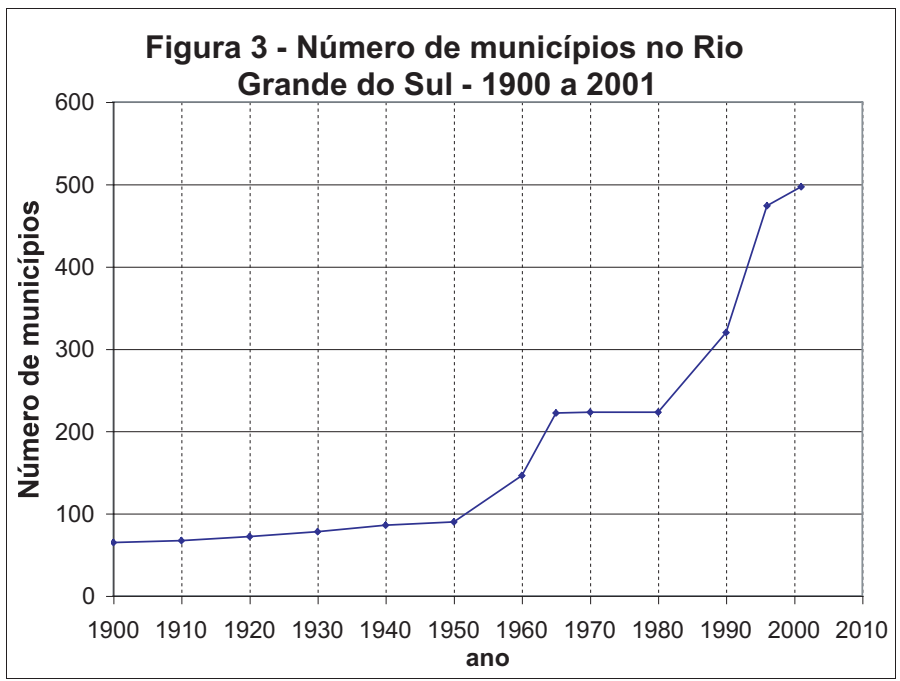

Fonte dos dados: Jardim (2001).

Sul poderiam todos ser classificados como municípios rurais no momento do seu primeiro recenseamento. 
Na verdade, a grande maioria dos novos municípios consegue sua emancipação com uma população próxima à do limite legal exigido. Portanto, a criação de novos municípios provavelmente está ligada a uma progressiva diversificação das atividades econômicas no meio rural, na medida em que esta está relacionada à formação de núcleos habitacionais, o que acaba resultando na implantação de uma infra-estrutura administrativa que confere a estes núcleos e ao seu entorno um "status" de município.

Baseado no exposto acima, nas próximas seções procurar-seá evidenciar os principais fatores responsáveis pelo desenvolvimento rural do Estado através da análise do contexto econômico regional relacionado aos desmembramentos municipais no Rio Grande do Sul.

\subsection{O processo de desmembramento municipal no Rio Grande do Sul}

Os primeiros municípios do Rio Grande do Sul surgiram com o desenvolvimento das charqueadas. Estas consolidaram as estâncias e provocaram um aumento da renda do setor pastoril permitindo uma dinâmica urbana inicialmente reduzida a algumas poucas cidades dentre as quais se destacam Rio Grande, Alegrete, Cachoeira, Pelotas e Bagé, com uma nítida predominância dos municípios na metade sul do Estado. A expansão da indústria do charque só não foi contínua até 1860 em virtude da Revolução Farroupilha que a prejudicou temporariamente entre 1835 e 1845 . A sua dinâmica econômica permitiu, no entanto, o surgimento de novos municípios de tal maneira que já em 1846, logo após o final da Revolução, o Estado contava com dezenove unidades político-administrativas concentradas, em sua maioria, na metade sul.

Entre 1841 e 1860, durante o período do auge do desenvolvimento das charqueadas, foram criados mais sete municípios dentre os quais apenas o de São Leopoldo, criado em 1846, deveu-se à economia dos colonos alemães. Mas a apropriação concentrada da terra e, consequientemente, da renda, determinou uma fraca dinamicidade econômica aos centros urbanos que surgem dadas as 
características concentradoras do sistema agrário baseado na pecuária extensiva no qual se alicerçam.

No final do século XIX, o charque "estava perdendo rapidamente a posição de principal produto de exportação do Rio Grande do Sul, pois passava a concorrer com a ascensão de outros produtos agrícolas, principalmente aqueles oriundos da Região Norte Colonial do Estado" (ROCHA, 1998: 50). Apesar da introdução de frigoríficos no início do século XX, a região sul nunca mais conseguiu apresentar um ritmo de crescimento que lhe permitisse fazer face à dinâmica econômica das regiões do norte, de predomínio da produção agrícola baseada no trabalho familiar. Assim, na região de predomínio da pecuária, surgiram apenas seis municípios novos ao longo de toda a primeira metade do século XX.

A partir de 1873, com a criação do município de Montenegro, iniciam-se, lentamente, as emancipações na região das Colônias Velhas, chegando-se ao limiar do século XX com 14 municípios nesta região. A partir de então, além de serem criados novos municípios nas Colônias Velhas, inicia-se também o processo nas Colônias Novas de tal forma que, em 1944, já existiam nas regiões de agricultura familiar, trinta e cinco municípios. Mas é a partir da segunda metade do século XX que as emancipações nas regiões coloniais passam por um extraordinário incremento com a criação de 140 novos municípios entre 1954 e 1965 , mais do que dobrando o número total existente no Estado em 1954, que era de 102 municípios. Neste período de 20 anos não é criado nenhum novo município nas regiões de agropecuária tradicional.

Esse processo é a expressão da dinâmica econômica e sóciopolítica da colonização das áreas de mato do Estado. Na medida em que a ocupação das matas avançava pelo interior do Estado ela era acompanhada, gradativa e rapidamente, pelo surgimento de povoados e a posterior criação de novos municípios. Assim, segundo LA SALVIA \& MARODIN (1976: 4), a atividade produtiva dos agricultores familiares "forçava a criação de muitos núcleos populacionais onde os colonos faziam o intercâmbio comercial de seus produtos agrícolas" em consequiência de sua dinamicidade populacional e econômica, dando origem a uma maior divisão do trabalho pela multiplicação de serviços sociais e culturais e 
pela crescente necessidade de atividades comerciais, de manufatura, de transporte, etc. Todas estas atividades eram remuneradas a partir do valor agregado gerado pelos agricultores em seus diversificados sistemas de produção. Os sistemas de produção predominantes entre os colonos de origem alemã eram os baseados na produção de milho e suíno, visando a produção de banha, tanto para o mercado interno quanto para a exportação (ROCHE, 1959; PEBAYLE, 1974). Entre os italianos teve papel importante, além da suinocultura, a produção de uva que permitiu o desenvolvimento de uma pujante indústria vinícola na região (PEBAYLE, 1974). No entanto, segundo PESAVENTO (1983: 75), a intermediação comercial prejudicava o agricultor, por isolá-lo dos estímulos do mercado na medida em que o comerciante assumia "uma função oligopólica/ oligopssônica, controlando a venda dos artigos não-coloniais e a compra dos produtos da região". Desta forma reduzia-se o desenvolvimento do pleno potencial da agricultura familiar. Estas dificuldades foram, em parte superadas pelo movimento cooperativista a partir dos anos $1911 \mathrm{e}$ 1912 (PESAVENTO, 1983).

A dinâmica de expansão da agricultura colonial deu-se em dois momentos distintos. O processo de desmembramento municipal foi influenciado por estes momentos.

O primeiro momento refere-se ao povoamento das chamadas "Colônias Velhas" que ocorreu a partir de 1824. Nesta fase o surgimento de municípios dava-se pela multiplicação de colônias que iam tomando corpo administrativo e dando origem aos municípios cujos distritos se transformavam, a seguir, em novos municípios. O ritmo de evolução municipal dava-se assim de uma forma bastante acelerada, "porque os municípios apresentavam uma densidade demográfica rural muito alta (superior a $50 \mathrm{hab} . / \mathrm{Km}^{2}$ ) e possuíam um grande número de distritos" (LA SALVIA \& MARODIN, 1976: 4).

O segundo momento corresponde ao da ocupação, pelos colonos, das chamadas "Colônias Novas". Isso ocorreu muito mais tarde, a partir de 1890, com a criação da Colônia Ijhuy em área pertencente ao município de Cruz Alta o qual já existia desde 1834. O processo de surgimento e multiplicação de municípios nas "Colônias Novas" foi semelhante ao das "Colônias Velhas". 
Até 1954 os municípios de uma maneira geral apresentavam expressiva área territorial e eram subdivididos em muitos distritos. A partir de então "desencadeou-se de modo efetivo o processo de municipalização com criação de inúmeros municípios" (LA SALVIA \& MARODIN, 1976: 4) com uma extraordinária aceleração de desmembramentos. Assim, entre 1954 e 1965, o número de municípios no Rio Grande do Sul passa de 102 para cerca de 242, sendo a grande maioria nas regiões das Colônias (Velhas e Novas), sendo que nenhum município foi criado nessa época nas regiões de pecuária extensiva do sul do Estado (regiões da Campanha e Serra do Sudeste).

Entre 1966 e 1980, justamente no período em que a agricultura do Rio Grande do Sul passou por profundas transformações tecnológicas, as quais provocaram uma grande diminuição do emprego na agricultura, apenas um município foi criado (JARDIM, 2001).

Mas a partir de 1981, o processo se intensifica novamente com a criação, nos anos 80, de 96 municípios. Nos anos 90 o processo de desmembramento municipal se intensifica ainda mais, com a criação de 153 novos municípios resultando nos 497 municípios atualmente existentes no Estado (JARDIM, 2001), cuja distribuição espacial indica uma nítida concentração nas regiões de agricultura familiar (Colônias Velhas e Novas), conforme pode ser constatado na Figura 4.

Em suma, a velocidade dos desmembramentos municipais ao longo do século XX foi sempre muito maior nas regiões de colonização, as quais apresentam predominância da agricultura familiar, do que nas regiões de campo em decorrência de sua maior dinamicidade econômica. Esta se deve às características de uma agricultura capaz de gerar a riqueza necessária à efetivação de uma dinâmica econômica mais abrangente e diversificada.

O grau de divisão territorial para efeitos administrativos parece ter chegado ao seu limite apesar de ainda haver demandas por criação de novos municípios em tramitação na Assembléia Legislativa do Estado. Estas demandas continuam sendo maiores nas regiões de agricultura familiar, o que expressa a capacidade destas de seguir originando núcleos populacionais geradores de bens e serviços. 


\subsection{As variáveis explicativas do desenvolvimento rural do Rio Grande do Sul}

A partir do exposto acima se levanta a hipótese da existência de três variáveis explicativas das diferentes dinâmicas de desenvolvimento rural observadas ao longo da história do Rio Grande do Sul. A primeira é a população rural presente nas suas regiões, a qual difere segundo a densidade demográfica. A segunda variável é o nível de renda das populações regionais e a terceira é a distribuição da renda no seio dessas populações. Estas variáveis podem condicionar o desenvolvimento rural de uma região através da sua influência sobre a demanda de bens e serviços locais como se procurará analisar formalmente no modelo descrito na próxima seção.

\section{Figura 4 - Divisão municipal atual e regiões do Rio Grande do Sul}

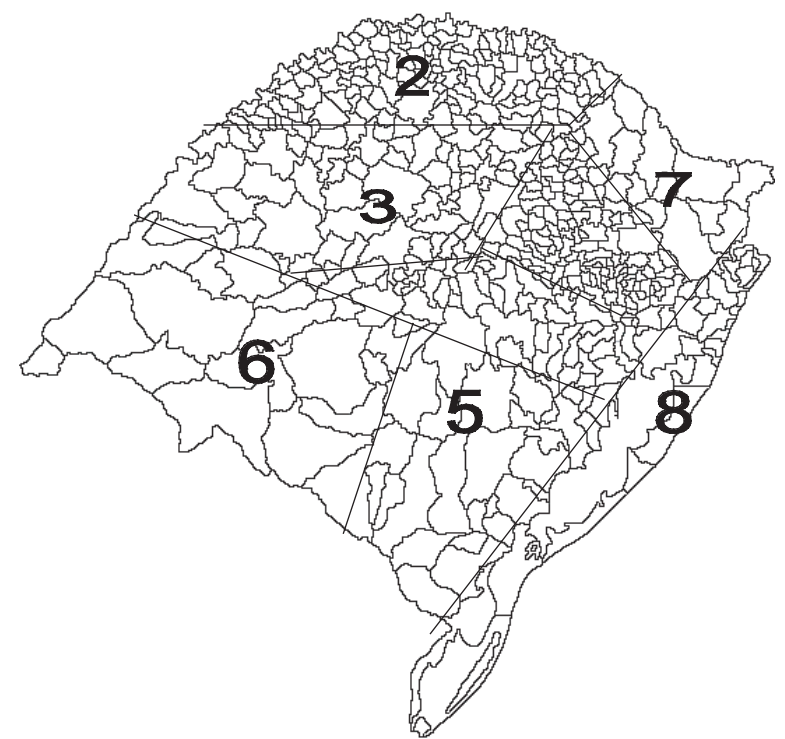

Legenda

1- Colônias Velhas; 2 - Colônias Novas; 3 - Planalto; 4 - Depressão Central;

5 - Serra do Sudeste; 6 - Campanha; 7 - Campos de Cima da Serra; 8 - Litoral

Fontes: divisão regional adaptada a partie de PEABAYLE (1974), divisão municipal obtida em JARDIM (2001) 


\section{Um modelo de demanda de bens e serviços locais}

Na tentativa de explicar os fatores responsáveis pelo desenvolvimento rural de uma região foi elaborado um modelo de demanda de bens e serviços locais. Tal modelo está baseado em uma generalização para produtos de consumo corrente da Lei de Engels (MOUNIER, 1992), ou seja, considerou-se que os bens e serviços de consumo corrente têm uma demanda que se comporta de forma semelhante à dos alimentos em relação ao aumento da renda dos consumidores. Assim, antes de discutir a estrutura formal deste modelo, é importante explicitar os pressupostos adotados para a sua elaboração, os quais são:

a) as comunidades rurais podem proporcionar uma disponibilidade limitada de bens e serviços, os quais concentram-se em atividades que exigem menos capital e tecnologia (predominância de atividades comerciais e de serviços em geral);

b) os bens e serviços passíveis de serem produzidos nas comunidades rurais são de consumo corrente, isto é, são produtos de baixo valor por unidade (o que exclui bens duráveis e "de luxo"), os quais são prioritariamente consumidos em relação a bens duráveis, a bens e serviços de luxo, ou em relação à poupança ou ao investimento;

c) os consumidores gastam apenas uma parte da sua renda com bens e serviços correntes, reservando a outra parte para bens e serviços de maior valor por unidade ou para constituir fundos de poupança ou investimento;

d) os bens e serviços locais são consumidos pelas pessoas residentes na própria região;

e) na medida em os agricultores se constituem na maioria da população rural, estes são os principais responsáveis pela sustentação da demanda de bens e serviços locais.

A partir destas constatações, elaboramos um modelo matemático simples para aprofundarmos a análise das relações entre a população rural (e, portanto, a densidade demográfica), o nível e a 
distribuição da renda desta população, e a demanda de bens e serviços locais. Procurando respeitar os pressupostos "b" e "c" descritos acima, adotamos uma função hiperbólica para descrever a relação entre, por um lado, a demanda média por bens e serviços locais e, por outro lado, a renda média e a sua distribuição. A demanda média é então multiplicada pela população para podermos obter a demanda total. Assim, temos,

$$
\begin{aligned}
& d=m-\frac{K}{r} \\
& D=d P
\end{aligned}
$$

onde

$d=$ demanda média de bens e serviços locais por pessoa; $m=$ demanda máxima de bens e serviços locais por pessoa; $K$ = escalar positivo (o significado econômico de " $K$ ” é discutido na próxima seção); $r=$ renda média por pessoa;

$D=$ demanda total de bens e serviços locais; $P=$ população rural.

Observando-se a equação (1) pode-se perceber que a demanda por pessoa de bens e serviços locais aproxima-se assintoticamente de um nível máximo, representado por " $m$ ", a medida em que a renda aumenta. Esta aproximação é mais rápida quanto menor é o valor de " $K$ ”, o qual desempenha um importante papel na relação entre a renda e a demanda de bens e serviços locais. Portanto, para a compreensão do modelo proposto, é importante que se proceda a uma discussão das possíveis interpretações do significado econômico que se pode atribuir à variável " $K$ ".

\subsection{Interpretação econômica da variável " $K$ "}

A variável " $K$ " indica a propensão ao consumo de bens e serviços correntes da população analisada. Assim, valores mais elevados 
de “ $K$ ” significam que uma dada população teria uma menor propensão ao consumo destes produtos (e, portanto, uma maior propensão a poupar, a investir ou a consumir bens duráveis e bens e serviços de luxo) em relação à uma população cujo comportamento é descrito por uma equação com valores de " $K$ ” mais baixos.

Para cada indivíduo isoladamente, o valor de " $K$ ”, em parte, é determinado pelas suas características culturais e psicológicas, sendo também influenciado pelo risco (ou incerteza) em relação aos resultados das suas atividades econômicas. Por exemplo, um indivíduo em dificuldades financeiras, portanto com tendência a uma maior aversão ao risco, em uma condição onde a dispersão dos resultados possíveis da sua atividade econômica é elevada, tenderia a ter uma preferência mais acentuada pela liquidez (BOUSSARD, 1987), o que pode afetar sua propensão ao consumo e, portanto, o valor de " $K$ " da equação que descreve sua demanda de bens e serviços de consumo corrente em relação a sua renda.

Mas para uma população considerada como um todo, o valor da variável " $K$ " também pode ser interpretado como uma expressão da influência da distribuição da renda sobre a demanda por bens e serviços locais (e, portanto, sobre o desenvolvimento rural). Isto porque o valor da variável " $K$ " difere se considerarmos no seu cálculo os agricultores individualmente ou a população como um todo, conforme demonstração a seguir.

Considerando o segundo membro da equação (1), para " $n$ " indivíduos teríamos,

$$
m-\frac{K}{r}=\frac{\sum_{i=1}^{n} m_{i}-\sum_{i=1}^{n} \frac{K_{i}}{r_{i}}}{n}
$$

$m$ = demanda máxima de bens e serviços por pessoa em média; $m_{i}=$ demanda máxima de bens e serviços de cada indivíduo i; $K_{i}=K$ de cada indivíduo; $r=$ renda média da população; 


$$
\begin{aligned}
& r_{i}=\text { renda de cada indivíduo } \mathrm{i} \\
& n=\text { número de indivíduos da população. }
\end{aligned}
$$

Considerando " $m_{i}$ ” o mesmo para todos os indivíduos, ou seja, $m_{i}=\mathrm{m}$,

$$
\sum_{i=1}^{n} m_{i}=n m
$$

substituindo (4) em (3) temos

$$
m-\frac{K}{r}=\frac{n m-\sum_{i=1}^{n} \frac{K_{i}}{r_{i}}}{n}
$$

ou seja,

$$
m-\frac{K}{r}=m-\frac{\sum_{i=1}^{n} \frac{K_{i}}{r_{i}}}{n}
$$

considerando $K_{i}$ igual para todos os indivíduos, e efetuando algumas transformações para isolar " $K$ ", temos,

$$
K=K_{i} r \frac{1}{n} \sum_{i=1}^{n} r_{i}^{-1}
$$

dado que a média harmônica $(H)$ é definida como (HOFFMANN, 1998), 
dado que a média harmônica $(H)$ é definida como (HOFFMANN, 1998),

$$
H=\left(\frac{1}{-} \sum_{n}^{n} r_{i}^{n}-1\right)^{-1}
$$

o seu inverso é

$$
\frac{1}{H}=\frac{1}{n} \sum_{i=1}^{n} r_{i}^{-1}
$$

substituindo (9) em (7), temos

$$
K=K_{i} \frac{r}{H}
$$

ou seja, a variável " $K$ " para o conjunto da população corresponde à variável " $K$ " (ou seja, " $K$ ” de cada indivíduo) multiplicada pela razão entre a média aritmética e a média harmônica da renda da população. Como a média harmônica é tanto menor que a média aritmética quanto maior a dispersão dos valores que a compõe (HOFFMANN, 1998), " $K$ " será tanto maior em relação à " $K$ ”" quanto maior a dispersão dos valores da renda da população. Assim, a variável " $K$ ” está diretamente relacionada com o perfil de distribuição da renda da população a qual determina que quanto maior a dispersão dos valores da renda da população, menor será a demanda de bens e serviços para um mesmo nível de renda médio.

Para ilustrar a capacidade do modelo proposto em captar a influência da distribuição da renda sobre a demanda de bens e serviços foram realizadas algumas simulações utilizando-se parâmetros obtidos a partir de entrevistas efetuadas junto a agricultores de Ijuí. Tais 
simulações são apresentadas na Figura 5 que mostra a influência da renda sobre a demanda de bens e serviços locais, considerando-se dois perfis de distribuição de renda. Um destes perfis corresponde a uma distribuição igualitária (isto é, toda a população recebe o mesmo valor de renda/pessoa) considerando-se que uma pessoa com uma renda muito elevada demandaria $\mathrm{R} \$ 2.040,00$ por ano de bens e serviços locais (ou seja, " $m$ " $=2.040$ ) e uma pessoa com renda de $\mathrm{R}$ \$ 1.000/ano demandaria R \$ 700/ano de bens e serviços locais, o que resulta, utilizando a equação (1), em um valor de “ $K$ ” de 1.340.000. O outro perfil de distribuição de renda considerado na simulação parte do mesmo valor de " $m$ ", porém com uma dispersão

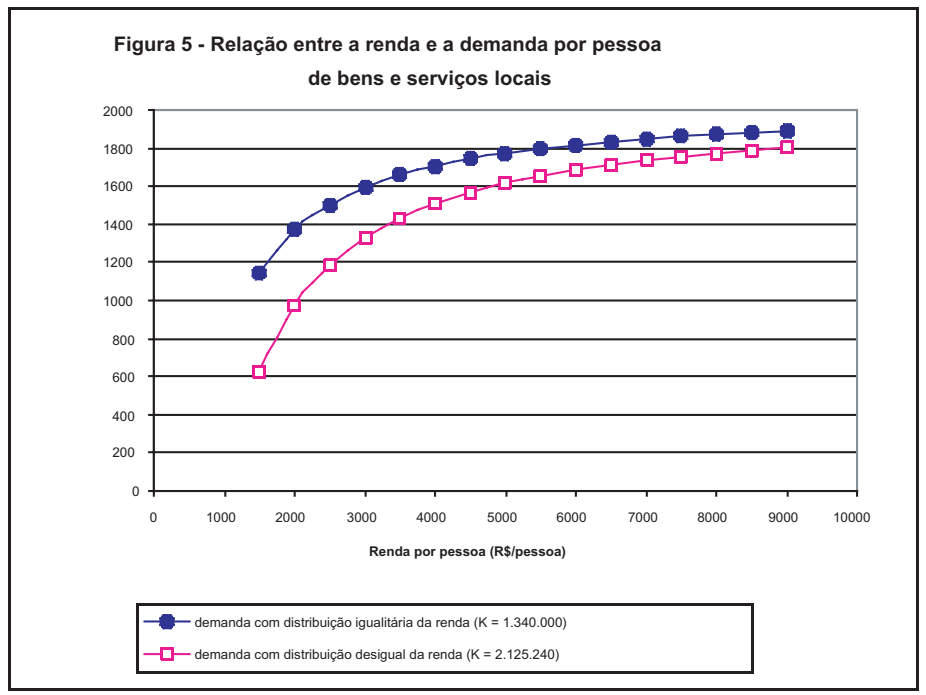

Fonte: simulação da pesquisa

da renda que traduz uma proporção de dois trabalhadores recebendo um salário de R 2.340/trabalhador/ano para cada trabalhador recebendo $\mathrm{R} \$ 10.320$ /ano, o que resulta uma média aritmética de $\mathrm{R} \$$ 5.000/trabalhador/ano e uma média harmônica de R $\$ 3.152,58 /$ trabalhador/ano. Combinando os valores da média aritmética, a média harmônica e o valor de " $K{ }_{i}$ " (" $K$ ” obtido anteriormente, correspondente 
ao de uma distribuição igualitária), através da equação (10) obtemos o valor de “ $K$ ”, de cerca de 2.125.240, que caracteriza o segundo perfil de distribuição de renda utilizado na simulação. Pode-se observar na Figura 5 que uma distribuição desigual da renda diminui a demanda de bens e serviços locais pelos agricultores. Por exemplo, para uma renda média de R \$ 2.000/pessoa, quando esta é distribuída de forma desigual, ela geraria uma demanda de bens e serviços locais de cerca de $\mathrm{R}$ \$ 1.000/pessoa, enquanto que a sua distribuição igualitária provocaria uma demanda de bens e serviços de quase $\mathrm{R} \$ 1.400 /$ pessoa. Assim, uma melhor distribuição de renda elevaria, neste caso, a demanda de bens e serviços locais de $50 \%$ para $70 \%$ da renda.

Outro aspecto a ser salientado a partir da observação da Figura 5 é que quanto menor a renda média, maior será o efeito da distribuição da renda sobre a demanda de bens e serviços locais. Por exemplo, enquanto que para o nível médio de renda de $\mathrm{R}$ \$2.000/pessoa discutido acima uma distribuição da renda levou a um aumento de $\mathrm{R} \$ 400 /$ pessoa na demanda de bens e serviços locais, para o nível de renda de $\mathrm{R} \$$ 8.000/pessoa, as mesmas medidas de distribuição de renda levariam a um aumento da demanda de bens e serviços locais de cerca de apenas R \$ 100/pessoa. Assim, embora estas simulações tenham um caráter apenas ilustrativo, na medida em que os dados obtidos foram insuficientes para uma validação estatística do modelo, elas indicam que em regiões pobres a distribuição da renda pode ser um fator mais importante para o desenvolvimento rural, através do seu efeito sobre a demanda de bens e serviços locais, do que em regiões de renda rural per capita elevada.

\section{Conclusões}

Os resultados obtidos neste trabalho indicam que a manutenção da população no campo, a ampliação da renda dos agricultores e a promoção de uma melhor distribuição desta renda podem ser elementos importantes de uma política de estímulo a atividades não-agrícolas no meio rural. Evidentemente, isto não exclui a necessidade de medidas específicas de apoio à criação de atividades não-agrícolas como, por exemplo, crédito, assistência técnica e capacitação de recursos 
humanos. Entretanto, a promoção de uma dinâmica da agricultura favorável à manutenção da população e da renda dos agricultores como, por exemplo, o estímulo, com eqüidade, de sistemas de produção com maiores resultados econômicos por unidade de superfície e com maior utilização de mão-de-obra, pode ser crucial para assegurar que medidas específicas destinadas à criação de atividades não-agrícolas não sejam neutralizadas por um contexto econômico local adverso.

Os dados obtidos neste trabalho indicam que a diminuição da demanda de mão-de-obra nos trabalhos agrícolas não foi um fator importante para o desenvolvimento rural do Rio Grande do Sul. Ao contrário, a análise da história do Estado efetuada neste trabalho indica que mesmo nos períodos em que não houve mudanças que poderiam levar a uma economia de mão-de-obra na agricultura observou-se que a liberação de mão-de-obra do campo devida ao crescimento vegetativo da população foi suficiente para a criação de atividades não-agrícolas nas regiões mais antigas de agricultura familiar do Estado, além de prover mão-de-obra para a colonização de novas terras.

Enfim, é importante ressaltar que os resultados obtidos neste trabalho são apenas preliminares, devendo ser confirmados por pesquisas mais precisas para que as conclusões por eles suscitadas possam ser consideradas em políticas de desenvolvimento. Entretanto, tais resultados indicam que um conhecimento adequado das interrelações entre as atividades econômicas agrícolas e não-agrícolas pode ser de crucial importância para o estabelecimento de políticas eficazes de desenvolvimento rural, especialmente para os municípios com menos de 20.000 habitantes, cuja maioria apresenta características predominantemente agrícolas.

\section{Referências Bibliográficas}

DEL GROSSI, M. E. \& GRAZIANO DA SILVA, J. Ocupações e Rendas Rurais no Brasil. In: ORNAs. Ocupações rurais não-agrícolas: oficina de atualização temática. Londrina, Iapar, 2000. BOUSSARD, J.-M. Economie de l'agriculture. Paris, Economica (Coleção Économie Agricole \& Agro-alimentaire), 1987. 
JARDIM, M. de L. T. Um século de população no Rio Grande do Sul. Porto Alegre, Fundação de Economia e Estatística Siegfried Emanuel Heuser, 2001 (CD-ROM).

LAURENTI, A. C. Terceirização dos trabalhos agrários e o "novo rural". In: ORNAs. Ocupações rurais não-agrícolas: oficina de atualização temática. Londrina, Iapar, 2000.

HOFFMANN, R., Estatística para Economistas. São Paulo, Editora Pioneira (Biblioteca Pioneira de Ciências Sociais. Economia), 1998. LA SALVIA, F. \& MARODIN, E. F. Evolução municipal: uma análise geográfica. Boletim Geográfico do Rio Grande do Sul.Porto Alegre, ano 21, n. 19, janeiro a dezembro de 1976.

MOUNIER, A. Les théories économiques de la croissance agricole. Paris, INRA-Economica, 1992.

MICHAIILOF, S. \& BRODIER, M. Guide Pratique d'Analyse de Projets. Èvaluation et Choix des Projets d'Investissements. Paris, Ed. Economica, 1987.

PEBAYLE, R. Eléveurs et Agriculteurs du Rio Grande do Sul (Brésil). Institut des Hautes Etudes de l'Amérique Latine. Paris, 1974 (Tese de Doutorado, documento não publicado).

PESAVENTO, S. J. RS: agropecuária colonial \& industrialização. Porto Alegre, Mercado Aberto, 1983.

ROCHA, J. M. \& BECKER, D.F. As raízes do declínio econômico da "metade sul" do Rio Grande do Sul. In Estudo \& Debate, UNIVATES, ano 5, n. 1, Lageado, FATES, 1998.

ROCHE, J. La Colonisation allemande et le Rio Grande do Sul. Institut des Hautes Etudes de 1'Amérique Latine. Paris, 1959 (Tese de Doutorado, documento não publicado).

VEIGA, J. E. da, et alii, O Brasil , J. E. da,. O Brasil Rural precisa de uma Estratégia de Desenvolvimento. Brasília, Convênio FIPE-IICA (MDA-CNDRS/NEAD), 2001 (disponível na Internet no endereço: www.nead.com.br/, acessado em 28 de março de 2002).

WANDERLEY, Urbanização e Ruralidade: Relações entre a Pequena Cidade e o Mundo Rural e Estudo Preliminar sobre os Pequenos Municípios em Pernambuco. Brasilia, NEAD/MAD, 2001 (disponível na Internet no endereço: www.nead.com.br/, acessado em 28 de março de 2002). 